\title{
A fresh study of optical and thermal properties of polystyrene solutions
}

\author{
S DURAI* and P RAMADOSS \\ P.G. and Research Department of Physics, A.M. Jain College, Chennai 600 114, India
}

MS received 10 October 2003

\begin{abstract}
Polymers have immense practical applications and one such polymer is polystyrene. It is a linear polymer and useful for plastic optical components. The optical and thermal properties of polystyrene solutions are investigated in this paper making use of the ultrasonic velocity and fluid parameters. The results reveal a number of significant informations.
\end{abstract}

Keywords. Polystyrene; Debye temperature; heat of mixing; molecular freelength; refractive index.

\section{Introduction}

A polymer of a particular group is characterized by the molecular weight of the monomer unit. To study the interactions in the solid state of the polymers few models have been suggested. One such model treats a polymer as an aggregate of fairly stiff tubes held together in approximately parallel bundles of forces arising from particleparticle potentials (Barker 1967). The structure of polymers has been related to internal pressure (Suryanarayana and Pugazhendhi 1986) and the same study has been extended to polystyrene solutions (Varadarajulu et al 1992). Some of the interesting properties of polystyrene like the Gruneissen parameter, specific heat and bulk modulus have also been reported. However, in this paper the authors have diverted their attention to the Debye temperature, relative association and optical property of polystyrene solutions. The three solvents considered are carbontetrachloride, benzene and carbondisulphide.

\section{Theory}

Three aspects have been given special attention.

(i) Relative association (RA) and heat of mixing: When a solution of polystyrene is prepared using a solvent (polar or non-polar), as the concentration increases there is a decrease in the availability of solvent molecules for polymer-solvent association. This is studied by the factor, RA, given by

$$
\mathrm{RA}=\left(\rho_{0} / \rho_{\text {mix }}\right)\left(u_{\text {mix }} / u_{0}\right),
$$

where $\rho_{0}$ and $\rho_{\text {mix }}$ are the density of solvent and solution, respectively and $u_{0}$ and $u_{\mathrm{mix}}$ are the sound velocity in pure solvent and solution, respectively.

\footnotetext{
*Author for correspondence
}

Polystyrene is a linear polymer. The theory of solubility based on the thermodynamics of polymer solutions is highly developed only for linear polymers in the absence of crystallinity. The heat of mixing per unit value can be approximated (Billmeyer 1984) as

$$
\Delta H=v_{1} v_{2}\left(\delta_{1}-\delta_{2}\right)^{2},
$$

where $v$ is the volume fraction and subscripts 1 and 2 refer to solvent and polymer, respectively. $\delta$ is known as the solubility parameter and $\delta^{2}$ the cohesive energy density. $\Delta H$ has been calculated for these systems.

(ii) Debye temperature: The solid like behaviour of liquids and solutions has been studied in some cases (Durai and Ramadoss 2002). In a polymer-solvent interaction, the change in thermal energy is due to (i) translational, rotational and vibrational energies of the components and (ii) the interchange energy. The change in internal energy is predominant and next comes vibrational energy, which is characterized by the Debye temperature. It is calculated from a knowledge of mean sound velocity, $u_{\mathrm{m}}$, using the formula

$$
\theta_{\mathrm{D}}=\left(h / k_{\mathrm{B}}\right)(3 N / 4 \pi V) u_{\mathrm{m}}
$$

and

$$
u_{\mathrm{m}}=\left[(1 / 3)\left(1 / u_{1}^{3}+2 / u_{\mathrm{t}}^{3}\right)\right]^{-1 / 3},
$$

where $u_{\mathrm{t}}$ and $u_{1}$ are the transverse and longitudinal sound velocity, respectively.

(iii) Optical property: The density rule is available for the calculation of refractive index. The authors have related the ultrasonic velocity to viscosity and surface tension (Durai and Ramadoss 2003). This empirical relation has been extended to binary mixtures (recently communicated). In this work the relation has been tried for finding the refractive index of polystyrene solutions. 
Table 1. Carbontetrachloride + polystyrene.

\begin{tabular}{|c|c|c|c|c|c|c|c|c|c|c|c|c|}
\hline Conc. $(\mathrm{g} / \mathrm{l})$ & $\rho^{*}$ & $u^{*}$ & $\eta^{*}$ & $L_{\mathrm{f}}$ & $\sigma$ & RA & $\lambda$ & $X$ & $n_{1}$ & $n_{2}$ & $\theta_{\mathrm{D}}$ & $\Delta H$ \\
\hline 0 & 1585.5 & $906 \cdot 7$ & $0 \cdot 84$ & $5 \cdot 7550$ & 0.0221 & $1 \cdot 0000$ & 0.8313 & $0 \cdot 1444$ & $1 \cdot 1958$ & 1.4607 & $46 \cdot 60$ & $* *$ \\
\hline 25 & 1575.6 & 914.7 & $2 \cdot 34$ & $5 \cdot 7220$ & 0.0224 & 0.9909 & 0.8235 & $0 \cdot 1439$ & $1 \cdot 3838$ & 1.4574 & 46.99 & $* *$ \\
\hline 50 & $1562 \cdot 2$ & 923.8 & $6 \cdot 24$ & $5 \cdot 6900$ & 0.0227 & 0.9792 & $0 \cdot 8126$ & $0 \cdot 1428$ & 1.5869 & 1.4529 & 47.41 & $* *$ \\
\hline 75 & $1553 \cdot 7$ & $930 \cdot 9$ & $10 \cdot 49$ & $5 \cdot 6621$ & 0.0229 & 0.9714 & 0.8059 & $0 \cdot 1423$ & 1.7061 & 1.4500 & $47 \cdot 77$ & $* *$ \\
\hline 100 & 1547.9 & 937.9 & 18.53 & $5 \cdot 6300$ & 0.0231 & 0.9653 & $0 \cdot 8007$ & $0 \cdot 1422$ & 1.8478 & 1.4479 & $48 \cdot 15$ & $* *$ \\
\hline 125 & $1537 \cdot 4$ & $946 \cdot 8$ & 37.99 & $5 \cdot 5964$ & 0.0234 & 0.9558 & 0.7925 & $0 \cdot 1416$ & - & 1.4446 & 48.57 & $* *$ \\
\hline 150 & $1531 \cdot 2$ & $955 \cdot 8$ & $48 \cdot 38$ & 5.5567 & 0.0237 & 0.9490 & $0 \cdot 7887$ & $0 \cdot 1415$ & - & 1.4425 & $49 \cdot 03$ & $* *$ \\
\hline
\end{tabular}

*Varadarajulu et al (1992); ** $\Delta H$ is zero for this system, since $\delta_{1}=\delta_{2}$ (see text).

Various symbols, their meanings with units used in the tables $1-3: \rho$, density $\left(\mathrm{kg} \mathrm{m}^{-3}\right) ; u$, ultrasonic velocity $\left(\mathrm{ms}^{-1}\right) ; \eta$, viscosity $\left(10^{-3}\right.$ $\left.\mathrm{Nsm}^{-2}\right) ; L_{\mathrm{f}}$, intermolecular freelength $\left(10^{-11} \mathrm{~m}\right) ; \sigma$, surface tension $\left(\mathrm{Nm}^{-1}\right)$; RA, relative association; $\lambda$, mean freepath $\left(10^{-11} \mathrm{~m}\right)$; $X$, ratio of mean freepath and intermolecular freelength; $n_{1}$, refractive index (using empirical relation); $n_{2}$, refractive index (using density rule); $\theta_{\mathrm{D}}$, Debye temperature $(\mathrm{K}) ; \Delta H$, heat of mixing $\left(\mathrm{J} / \mathrm{m}^{3}\right)$.

Table 2. Benzene + polystyrene.

\begin{tabular}{ccccccccccccc}
\hline Conc. $(\mathrm{g} / \mathrm{l})$ & $\rho^{*}$ & $u^{*}$ & $\eta^{*}$ & $L_{\mathrm{f}}$ & $\sigma$ & $\mathrm{RA}$ & $\lambda$ & $X$ & $n_{1}$ & $n_{2}$ & $\theta_{\mathrm{D}}$ & $\Delta H$ \\
\hline 0 & $872 \cdot 6$ & $1278 \cdot 3$ & $0 \cdot 56$ & $5 \cdot 5020$ & $0 \cdot 0233$ & $1 \cdot 0000$ & $0 \cdot 8023$ & $0 \cdot 1458$ & $1 \cdot 1777$ & $1 \cdot 5011$ & $68 \cdot 11$ & - \\
25 & $877 \cdot 9$ & $1281 \cdot 4$ & $1 \cdot 77$ & $5 \cdot 4721$ & $0 \cdot 0236$ & $1 \cdot 0053$ & $0 \cdot 8064$ & $0 \cdot 1474$ & $1 \cdot 3959$ & $1 \cdot 5047$ & $68 \cdot 18$ & $0 \cdot 0180$ \\
50 & $883 \cdot 5$ & $1284 \cdot 3$ & $4 \cdot 35$ & $5 \cdot 4297$ & $0 \cdot 0239$ & $1 \cdot 0117$ & $0 \cdot 8130$ & $0 \cdot 1497$ & $1 \cdot 6030$ & $1 \cdot 5085$ & $68 \cdot 44$ & $0 \cdot 0343$ \\
75 & $888 \cdot 8$ & $1287 \cdot 8$ & $8 \cdot 80$ & $5 \cdot 4114$ & $0 \cdot 0242$ & $1 \cdot 0161$ & $0 \cdot 8171$ & $0 \cdot 1510$ & $1 \cdot 7875$ & $1 \cdot 5121$ & $68 \cdot 47$ & $0 \cdot 0500$ \\
100 & $893 \cdot 1$ & $1291 \cdot 2$ & 14.99 & $5 \cdot 3842$ & $0 \cdot 0245$ & $1 \cdot 0201$ & $0 \cdot 8209$ & $0 \cdot 1525$ & $1 \cdot 9479$ & $1 \cdot 5151$ & $68 \cdot 52$ & $0 \cdot 0656$ \\
125 & $898 \cdot 5$ & $1294 \cdot 3$ & $41 \cdot 87$ & $5 \cdot 3551$ & $0 \cdot 0247$ & $1 \cdot 0251$ & $0 \cdot 8250$ & $0 \cdot 1541$ & - & $1 \cdot 5188$ & $68 \cdot 62$ & $0 \cdot 0790$ \\
150 & $899 \cdot 9$ & $1297 \cdot 8$ & $70 \cdot 36$ & $5 \cdot 3365$ & $0 \cdot 0250$ & $1 \cdot 0261$ & $0 \cdot 8279$ & $0 \cdot 1551$ & - & $1 \cdot 5097$ & $68 \cdot 71$ & $0 \cdot 0956$ \\
\hline
\end{tabular}

Table 3. Carbondisulphide + polystyrene.

\begin{tabular}{|c|c|c|c|c|c|c|c|c|c|c|c|c|}
\hline Conc. $(g / l)$ & $\rho^{*}$ & $u^{*}$ & $\eta^{*}$ & $L_{\mathrm{f}}$ & $\sigma$ & RA & $\lambda$ & $X$ & $n_{1}$ & $n_{2}$ & $\theta_{\mathrm{D}}$ & $\Delta H$ \\
\hline 0 & $1253 \cdot 2$ & $1127 \cdot 0$ & $0 \cdot 34$ & $5 \cdot 2075$ & 0.0231 & $1 \cdot 0000$ & 0.7147 & $0 \cdot 1372$ & 1.0730 & 1.6276 & 67.71 & - \\
\hline 25 & $1251 \cdot 7$ & $1131 \cdot 0$ & 0.94 & $5 \cdot 1943$ & 0.0233 & 0.9976 & 0.7148 & $0 \cdot 1376$ & $1 \cdot 2322$ & 1.6266 & 67.76 & 0.0025 \\
\hline 50 & $1247 \cdot 0$ & $1135 \cdot 1$ & $2 \cdot 77$ & $5 \cdot 1831$ & 0.0235 & 0.9927 & 0.7136 & $0 \cdot 1377$ & 1.4294 & 1.6237 & $67 \cdot 77$ & 0.0051 \\
\hline 75 & $1245 \cdot 5$ & $1138 \cdot 9$ & $7 \cdot 75$ & $5 \cdot 1689$ & 0.0237 & 0.9904 & $0 \cdot 7134$ & $0 \cdot 1381$ & 1.6420 & 1.6228 & 67.83 & 0.0073 \\
\hline 100 & $1241 \cdot 0$ & 1142.9 & $28 \cdot 70$ & $5 \cdot 1602$ & $0 \cdot 0238$ & 0.9857 & 0.7122 & $0 \cdot 1380$ & 1.9732 & 1.6199 & $67 \cdot 84$ & 0.0096 \\
\hline 125 & $1236 \cdot 1$ & $1147 \cdot 7$ & $76 \cdot 75$ & $5 \cdot 1511$ & 0.0240 & 0.9805 & 0.7107 & $0 \cdot 1379$ & - & 1.6169 & 67.88 & 0.0119 \\
\hline 150 & $1232 \cdot 8$ & $1151 \cdot 2$ & $120 \cdot 00$ & $5 \cdot 1405$ & 0.0242 & 0.9768 & 0.7097 & $0 \cdot 1372$ & - & 1.6149 & 67.93 & $0 \cdot 0138$ \\
\hline
\end{tabular}

\section{Results and discussion}

The ultrasonic velocity and viscosity data for various concentrations of the systems are those obtained by Varadarajulu et al (1992). Surface tension $(\sigma)$, intermolecular freelength $\left(L_{\mathrm{f}}\right)$, mean freepath $(\lambda)$ and refractive index $(n)$ obtained by us are given in tables 1-3 for carbontetrachloride + polystyrene, benzene + polystyrene and carbondisulphide + polystyrene, respectively. It is observed that the relative association shows a continuous decreasing or increasing trend in the solutions. The observation is in accordance with the change in mean freepath.

The values of $\theta_{\mathrm{D}}$ in all the cases assume values in the range $46 \mathrm{~K}-68 \mathrm{~K}$ reflecting the low boiling point of the solute. Further, heat of mixing another thermal data has very small value and is zero in the case of polystyrene with carbontetrachloride. This indicates a readjustment of internal and vibrational energies.

The refractive index values calculated from density rule and the empirical relation are of the same order. However, in some cases the values are slightly high and they are not reproduced in the tables. It may be due to the fact that the solutions become less transparent.

\section{Conclusion}

Thus the systematic analysis of polymer solutions presented here reveals interesting features. However, a decisive conclusion could be drawn only after several such investigations.

\section{References}

Barker R E 1967 J. Appl. Phys. 384234

Billmeyar F W 1984 The textbook of polymer science (New York: John Wiley \& Sons Inc), 3rd ed.

Durai S and Ramadoss P 2002 Bull. Pure \& Appl. Sci. D21 59

Durai S and Ramadoss P 2003 Acta Acustica 89173

Suryanarayana C V and Pugazhendhi P 1986 Indian J. Pure \& Appl. Phys. 24406

Varadarajulu A, Suryanarayana C V and Pugazhendhi P 1992 Acta Ciencia Indica XVIII 107 